\title{
Avoiding the Pitfalls in International Collaborations - A Case Study
}

\section{Dr. Cem Karacal, Southern Illinois University, Edwardsville}

Dr. Cem Karacal is a Professor of Industrial Engineering and Dean of the School of Engineering at Southern Illinois University Edwardsville. He obtained his Ph.D. and M.S. degrees from Oklahoma State University in 1991 and 1986, respectively. His received his B.Sc. degree from Middle East Technical University, Ankara, Turkey in 1982. He has experience in industry and academia. His main research and teaching interest areas are simulation modeling, quality control, operations research, and facilities layout. Before joining to SIUE he worked at Rochester Institute of Technology as a faculty member and Computer Integrated Manufacturing System project coordinator for RIT's integrated circuit factory. He is a senior member of IIE and SME, and a member of ASEE, Alpha Pi Mu and Tau Beta Pi.

\section{Dr. Hasan Sevim, Southern Illinois University, Edwardsville}

Dr. Hasan Sevim obtained his B.S. degree in mining engineering in 1974 from Istanbul Technical University, Turkey. He obtained his M.S. and Ph.D. degrees in 1978 and 1984, respectively, from Columbia University, New York. In 1984, he joined the College of Engineering at Southern Illinois University (SIU), Carbondale as an assistant professor in the Department of Mining Engineering. He served as the Associate Dean of the College of Engineering from 1998 to 2006. He was appointed Dean of the School of Engineering at SIU Edwardsville in August 2006. He retired in 2016.

Until 2000, most of Dr. Sevim's publications were in mine systems optimization and open pit mine production planning. After 2000, in parallel with his administrative appointments, he mostly published in the area of engineering education. 


\title{
Avoiding the Pitfalls in International Collaborations - A case study
}

\author{
Hasan Sevim and S. Cem Karacal \\ hsevim@siue.edu and skaraca@siue.edu \\ Southern Illinois University Edwardsville, School of Engineering, \\ Edwardsville, IL 62026
}

\section{Introduction}

In 2007, the School of Engineering at Southern Illinois University Edwardsville (SIUE) started a dual-diploma program in Industrial Engineering with Istanbul Technical University (ITU). This program was the first dual-diploma program in Industrial Engineering both in the USA and Turkey. SIUE is a Professional Doctorate University with an enrollment of 14,000 and ITU is one of the premier engineering schools in Turkey with an enrollment of 20,000. The industrial engineering programs in both institutions are ABET accredited, and the instruction medium at ITU is in English for the dual-diploma students. This is the sole dual-diploma program at SIUE, whereas ITU has several others with USA institutions in fields other than industrial engineering.

In Turkey, students are admitted into this program via a nation-wide university placement exam taken annually by about 1.5 million students. This dual-diploma program typically admits students from the top $3 \%$ based on quantitative scores. The discipline is highly popular in Turkey, as many consider it as an engineering degree providing upward mobility to management or executive positions. A diploma from SIUE makes the degree attractive in the Turkish job market, as the graduates of the program have proven English language skills and academic experience in the U.S.

The TOEFL score is used to gauge student admission to the freshman class at ITU. Students who cannot score the minimum requirement of 79 in TOEFL attend English as a Second Language (ESL) program at ITU until they secure 79. Each year 35 students are admitted to the program. Upon successful completion of the academic requirements at both institutions, students are awarded a B.Sc. degree in Industrial Engineering by both SIUE and ITU.

\section{Brief Program Outline}

The program was designed in such a way that the students were exposed to both general education and industrial engineering courses at both institutions. This, we anticipated, would make the graduates more valuable at job markets both in Turkey and the USA. Therefore, unlike a typical $2+2$ program (the first two years at one institution and the next two at the other) it was decided that the students study freshmen and junior years at ITU and sophomore and senior years at SIUE. This implementation required ITU to open additional sections of Industrial Engineering courses to be taught in English in the junior year. Faculty who were assigned to teach these classes received substantial overload payments. 
It is noted that SIUE required completion of 128 credit hours for graduation, whereas ITU required 142. It was agreed that ITU would teach 37 credit hours in freshmen and 39 in junior year for a total of 76 hours, whereas SIUE would teach 32 credit hours in sophomore year and 34 hours in senior year for a total of 66 hours.

The enrollment and graduation statistics over the years are shown in Table 1. Enrollment numbers reflect both sophomores and seniors each year. As seen, 193 students have been graduated as of May 2018. Our information indicates that some of these graduates were engaged in graduate studies, but the majority found prestigious positions in the field of industrial engineering in Turkey and a few in the USA.

Table1. Dual-diploma enrollment and graduation statistics at SIUE

\begin{tabular}{|l|c|c|c|c|c|c|c|c|c|c|c|c|}
\hline & $\mathbf{2 0 0 8}$ & $\mathbf{2 0 0 9}$ & $\mathbf{2 0 1 0}$ & $\mathbf{2 0 1 1}$ & $\mathbf{2 0 1 2}$ & $\mathbf{2 0 1 3}$ & $\mathbf{2 0 1 4}$ & $\mathbf{2 0 1 5}$ & $\mathbf{2 0 1 6}$ & $\mathbf{2 0 1 7}$ & $\mathbf{2 0 1 8}$ & Total \\
\hline $\begin{array}{l}\text { Enrolled at } \\
\text { SIUE }\end{array}$ & 4 & 19 & 38 & 43 & 69 & 58 & 64 & 61 & 63 & 45 & 57 & 521 \\
\hline Graduated & & & & 4 & 19 & 30 & 24 & 31 & 31 & 27 & 27 & $\mathbf{1 9 3}$ \\
\hline
\end{tabular}

A comprehensive description of this program, covering topics such as curriculum, new student orientation, transition to SIUE, housing, academic culture of SIUE and ITU, classroom conduct, academic honesty, life in the USA, out-of-sync-students, etc. was provided in an earlier publication [1]. Therefore, in this paper we will present only possible pitfalls based on our recent experience.

\section{Program termination and assessment of the specified reasons}

It is noted that in Turkey chancellors are appointed by the president of the country. A chancellor (rector) can be appointed for a maximum of two four-year terms. Typically, each chancellor appoints his/her administrative cadre, including the deans. SIUE team worked with three different groups of ITU administrators since the inception of the program in 2007. The SIUE portion of the program has been receiving positive evaluations from students, alumni, parents, and especially from all three ITU groups of administrators. The founding vice-rector made the following statement, "We launched the SIUE-ITU industrial engineering dual-diploma program in 2007. At the time, I was the vicerector overseeing all ITU dual-diploma programs. The program with SIUE flourished in a short period of time and became one of the best, if not the best." Similar praises were made by the second group of administrators (2008-2012) when they came to visit the SIUE campus and participated in the Commencement ceremonies. As a matter of fact, based on positive assessment of SIUE's program management by ITU's third group of administrators in November 2015, it was mutually agreed to extend the Memorandum of Understanding (MOU) for an additional 5 years, to be effective until 2020. In 2016, only three months after the renewal of the MOU, ITU notified SIUE of the unilateral termination of the program, invoking a clause in the MOU, which reads as follows: " $V$. Term- The term of this MOU shall be from May 30, 2015, to May 30, 2020. This MOU may be renewed only by written agreement of the parties. Either party may terminate this MOU with oneyear written notice to the other party." 
When asked, ITU gave the following two reasons for unilateral termination:

1. The ranking of SUE's industrial engineering program in the USA.

2. Negative feedback from the students regarding their educational experience at SIUE.

When the MOU was signed in 2007, the industrial engineering program at SIUE was not ranked in the top 50 in the USA (U.S. World News and World Report rankings). The ranking stayed steady during the program in the last decade. SIUE worked with ITU's first group of administrators from 2007 to 2008. During this period, the ITU administrators did not raise any questions about SIUE's ranking. SIUE worked with ITU's second group of administrators from 2008 to 2012. Again, during this period, the ITU administrators did not raise any questions about SIUE's ranking. The first time SIUE heard about the ranking concern from ITU was with the third group of administrators in 2013. However, after two consecutive SIUE campus visits in 2014 and 2015, the visiting ITU administrator agreed that this was an excellent program and that the agreement should continue as planned. Consequently, the agreement was renewed for 2015 through 2020. Interestingly, this criticism of the ranking was given in 2016, only three months after the renewal of the agreement. When the interaction between the two institutions is reviewed chronologically, SIUE's ranking does not seem to be a plausible cause for termination of the program.

As for the second reason, "negative feedback of the students", again, we were confident that it could not be a plausible reason. The student evaluations we have been collecting over the years have indicated the opposite. When ITU was asked by SIUE to substantiate this claim with supporting documentation, nothing was provided.

At SIUE, seniors are given surveys each year to assess the dual-diploma program. This has been done conscientiously over the years as part of the ABET accreditation process. SIUE has shared some of the outcomes of these surveys with ITU so that they could improve their management approach, especially in the areas of "program coordinator" and "program management." A few relevant items from these surveys are shown in Figure 1 in a comparative format. The data presents the average score for each question over five consecutive years, from 2012 to 2016 . The survey questions are:

Q1-2 Friendliness and helpfulness of the program coordinator at SIUE/ITU

Q3-4 Friendliness and helpfulness of department faculty at SIUE/ITU

Q5-6 Industrial Engineering courses at SIUE/ITU

Q7-8 Industrial Engineering technical elective choices at SIUE/ITU 


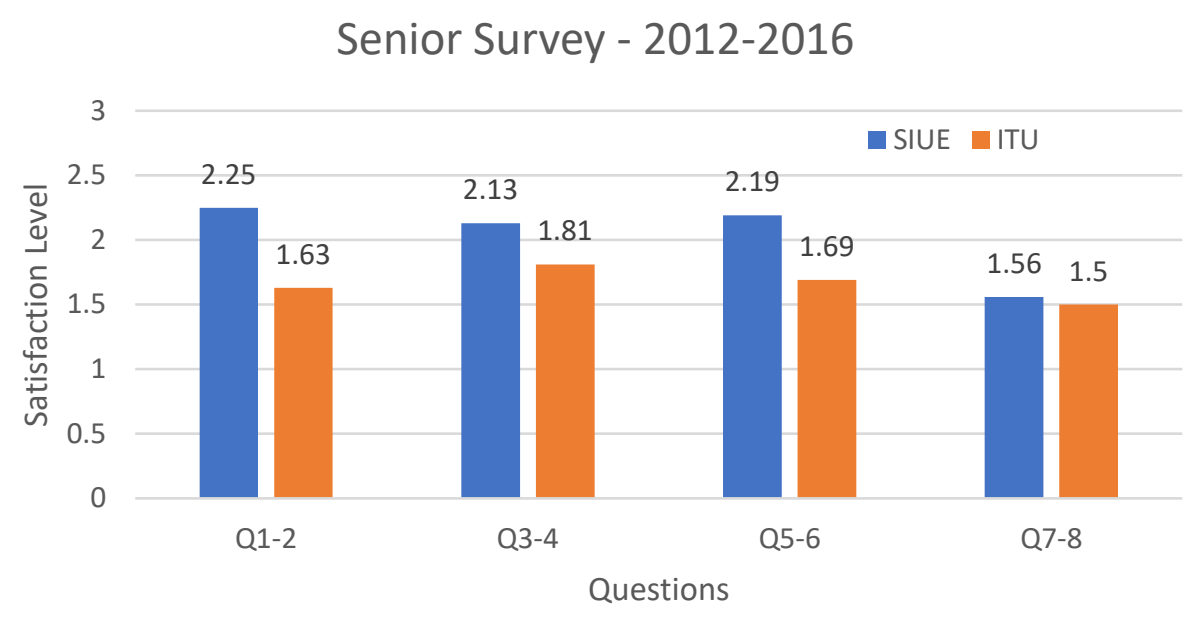

Satisfaction Levels: not satisfied-1, satisfied-2, very satisfied-3

Figure 1. Dual-diploma student satisfaction survey results (2012-2016)

As seen in Figure 1, the seniors had been consistently more satisfied at SIUE than ITU. Further information about the annual program survey results can be seen in [1]

Even though we have been surveying each senior class annually for the educational experience they have been receiving at SIUE, we decided to survey the alumni and the 2018-19 academic year students in a comparative fashion, that is SIUE versus ITU, to assess the validity of the outcomes of our 2012-2016 senior surveys. We thought that especially alumni would provide an objective evaluation of their educational experience in both institutions. The 15-question-survey is included in the appendix.

We received 40 responses from 87 alumni, representing a $46 \%$ response rate, and 17 responses from a total of 55 current students representing a $31 \%$ response rate. Although there are 193 alumni, the SIUE coordinator has up to date contact email addresses of only 87 alumni. The responses of the alumni and the current students to the first 10 questions are shown in Figures 2 and 3, respectively. The 10 comparative questions are:

Q1-2 The education I received at SIUE/ITU prepared me well for my professional life and/or graduate studies. (agree and strongly agree options are tabulated in Fig. 2, 3 and 4)

Q3-4 The guidance I received from the program coordinator at SIUE/ITU was:

(satisfactory, good, very good and excellent options are tabulated in Fig. 2, 3 and 4)

Q5-6 The professors at SIUE/ITU were knowledgeable in their field.

(agree and strongly agree options are tabulated in Fig. 2, 3 and 4)

Q7-8 The professors at SIUE/ITU were approachable and showed interest in me.

(agree and strongly agree options are tabulated in Fig. 2, 3 and 4)

Q9-10 Overall, the education I received at SIUE/ITU was:

(good, very good and excellent options are tabulated in Fig. 2, 3 and 4) 


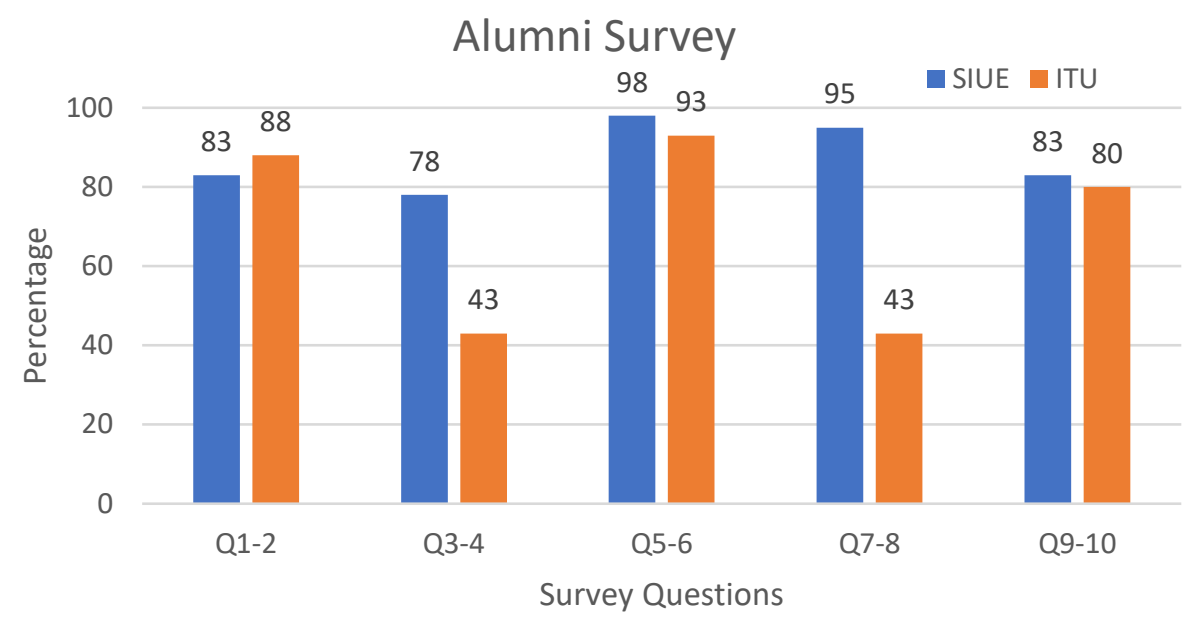

Figure 2. Alumni educational experience survey results,

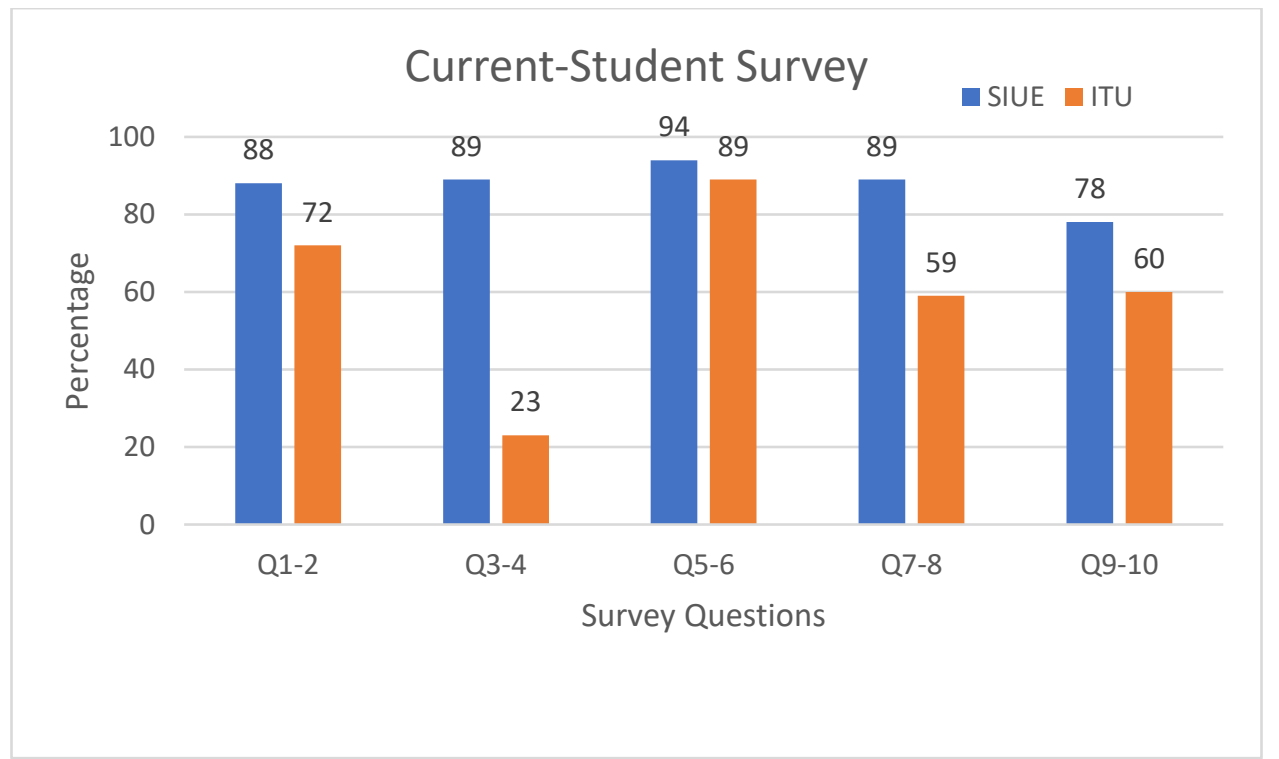

Figure 3. Current-student educational experience survey results

It is seen in both graphs that in all areas, but one, SIUE was rated higher than ITU. ITU was rated slightly higher than SIUE in the area of preparation for professional life and/or graduate studies by the alumni (Q1-2 in Figure 2). It is abundantly evident that SIUE was preferred over ITU when alumni and 2018-19 academic year students at SIUE were asked about the "guidance received from the program coordinators (Q3-4)", and the "approachability of the professors and the interest they showed in the students (Q67)". For the questions of the "knowledge of the professors in their fields (Q5-6)" and "overall quality of the education (Q9-10)", despite slight advantage of SIUE, one may conclude that the respondents were content with both institutions. 
Since the responses of both groups (alumni and current seniors) are very similar, we decided to combine the data, which would increase the sample size and improve the reliability of the outcomes. The combined data is shown in Figure 4. As seen, SIUE's ratings are higher than that of ITU in all categories, except the first category where they are equal.

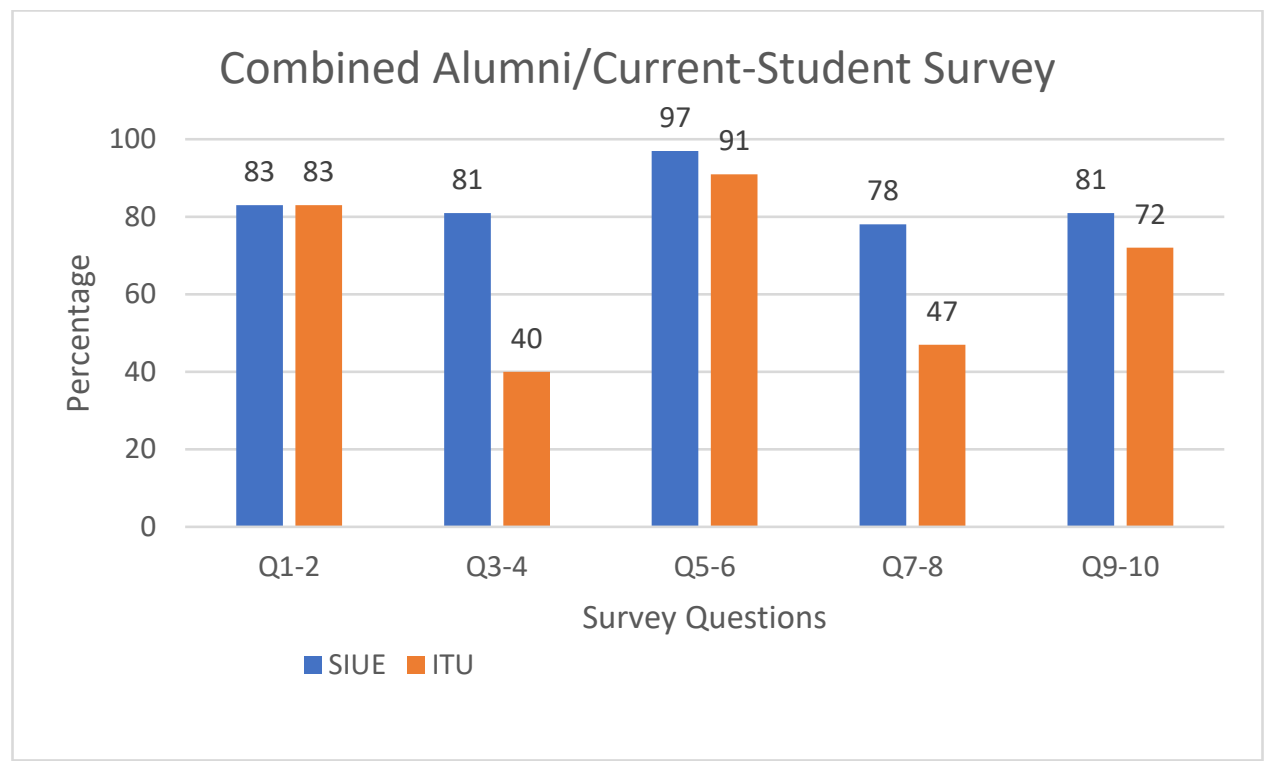

Figure 4. Combined alumni/current-student survey results,

The responses to Questions 11, 12,13, 14 and 15 of the alumni/current-student survey are presented below:

\section{$Q$ 11. Have you ever been surveyed by ITU administrators regarding your educational experience?}

Thirty-five (35) of the 40 alumni and 17 of the 18 current students responded "no" to this question. From this overwhelming negative response, we concluded that the five alumni and one senior who said "yes" might have had personal conversation with some of the ITU administrators. However, it is clear that the students have never been formally surveyed during their studies at ITU. This brings up an important question; how did the ITU official(s) base their unilateral termination of the agreement on "the negative feedback of the students" when there was no evidence of official student feedback since the inception of the program?

\section{$Q 12$. If the program were to continue, would you recommend it to a friend or relative?}

Fourteen (14) of the 40 alumni and 2 of the 18 current students indicated they would not recommend the program. Only four alumni gave reasons for not recommending it; two indicated that they would not recommend it because SIUE is not well-known in the USA, one indicated that s/he could not find a job in the USA with an SIUE diploma, and another one cited the high cost of the program due to continuous devaluation of Turkish Lira. 


\section{$Q$ 13. In your opinion, what might be the reason(s) ITU administration terminated this program?}

Most of the respondents expressed surprise and disappointment for the termination of the program. A good number of them think that SIUE ranking must have been the real reason behind program termination. Yet, a few of them mentioned that the universities with which ITU has dual-diploma programs are not highly ranked either. And, therefore they added, the reason ITU decided to terminate the program might be some internal issues within the ITU's industrial engineering program. A few others cited lack of administrative skills and attention at ITU. One respondent suggested that in the future SIUE ought to consider collaboration with private universities where the administrators are not appointed by the governing political party.

\section{Q 14. Please tell us your current occupation?}

Twenty-eight (28) of the 40 alumni respondents answered this question. Of the 28,5 were graduate students. Almost all the positions were professional positions in industrial engineering field or closely related fields.

\section{Q15. Any additional comments or suggestions you might make?}

Sixteen alumni and seven current students made comments and/or suggestions. All current students indicated that they are happy with the program and they wish the program could continue. One senior complained about overlapping subjects in various courses. Most of the alumni expressed regret and disappointment that the program from which they graduated has been terminated. They also expressed appreciation to the professors who cared about them in both institutions. A couple of them expressed discontent towards SIUE because they said they could not find jobs in the USA with a SIUE diploma. Three alumni pointed out wide-spread plagiarism among dual-diploma students, and professors who are asking the same old exam questions year after year. Apparently, these exams have been circulated among the dual-diploma students.

\section{The role of the coordinator and the administrative cadre}

At the outset of the program design, the crucial role of the coordinator and the required vigilance of the administrators were recognized by the partners for the success of the program. Therefore, the following clauses were inserted in the MOU.

4. Each partner will continue to appoint a faculty coordinator for the dual-diploma, joint degree program. The Coordinators will continue to plan and implement the curriculum each year, oversee the academic advising of students, monitor the progress of students, and collaborate in the solutions of problems that arise. Coordinators will continue to communicate with each other regularly to be sure the delivery of courses is organized in such a way that students can meet the requirements efficiently. Long distance advising, principally through electronic communication, will take place to facilitate the students' transition between campuses.

11. ITU and SIUE will maintain their protocol to evaluate each degree program on a regular basis. Both sides agree to work collegially to identify solutions to problems and make improvements in order to offer smoothly functioning, efficient, quality programs.

The operation of the dual-diploma program requires timely and accurate exchange of information between several university offices, because some of the processes and 
records for these students are not the same as domestic or other international students. Therefore, these students are given a special tag in SIUE's Student Information System. Each university office has a designated, and an alternate, staff member(s) who are familiar with the dual-diploma program issues. The Industrial Engineering program at SIUE is supported by International Student Services Office, Admissions, University Housing, and Registrar. The program coordinator acts as the central person who collects and relays information about various processes and exceptions between offices.

As mentioned before, each newly appointed rector at ITU appoints in turn his/her own staff. This frequent turnover of administrators hampers the operation principles agreed upon in clauses 4 and 11 of the MOU given above. Most of the time, the newly appointed personnel at ITU are not familiar with the operation of the dual diploma program because of the loss of the institutional memory. For example, ITU has appointed four different coordinators and three deans since the inception of the program. Unfortunately, the know-how was not transmitted from one administrator to the next. The student complaints emanating from this sort of disconnect at ITU are reflected on the comments received in alumni and student surveys. One alum commented that when s/he sought help from the coordinator, the coordinator was trying to learn from her/him.

In summary, the results of the annual surveys given to seniors by SIUE since 2008 have not indicated any significant complaints that could be construed as "negative feedback regarding their educational experience at SIUE." We noted that students have been complaining about several issues in both institutions, but overall, they were consistently rating SIUE more positively than ITU. Additionally, the results of the most recent survey given to alumni and 2018-19 students did not indicate any major issues that could be construed as "negative feedback regarding their educational experience at SIUE." On the contrary, based on the outcomes, one may conclude that the alumni valued their educational experience at SIUE more than ITU. Therefore, it is not realistic to use "student feedback" as a cause to terminate the program unilaterally.

\section{A probable cause behind the unilateral termination of the program}

Beginning with 2015, SIUE received complaints from students that some of the material in the required industrial engineering courses they were taking at SIUE were already covered in courses they took at ITU. An example of this was Supply Chain Management Topics. Furthermore, ITU wanted to open a set of new technical electives that were closely related to required industrial engineering courses taught at SIUE. SIUE expressed concerns about significant overlaps among these new courses and some of the materials being repeated in the current courses. The administrators at ITU were not happy since these were the courses they wanted to assign to their newly recruited faculty so that they would receive overload contracts for these additional courses. We think that this issue was pivotal in the abrupt termination of the dual diploma partnership by ITU three months after renewing the agreement for another 5 years.

\section{Recommendations to institutions who contemplate dual-diploma-like agreements:}


Our experience with this program over a decade has taught us that in order to run a successful program there has to be continuous (annual) evaluation of the program components, including evaluation of the administrators of both institutions. These evaluations must be done based on engineering professional ethics. The evaluation records must be used for program improvement, as well as for substantiation for program termination. There should be no room for opinions, feelings, and/or hidden agendas. Therefore, a mutually agreed upon evaluation scheme must be designed at the beginning and the principles of it must be entered in the MOU. Additionally, the MOU must have a clause that would underline the consequences in case a party unilaterally terminates the program without substantiation.

Some of the critical areas where there may be pitfalls are listed below:

1. Memorandum of Understanding: Define the duration of the agreement, the conditions under which it will be renewed and time of renewal. State clearly the causes of program termination. Require documentation to substantiate the cause(s) of termination.

2. Program Evaluation: Design a mutually agreed upon annual program evaluation scheme. This evaluation scheme must include courses, faculty, as well as the administrators of both institutions; deans, program chairs, coordinators, advisors, and support staff.

3. Curriculum: Design a curriculum that would bring together the best of the two institutions. Have a clear understanding of the distribution of the general education, science and math, as well as the fundamental engineering courses. Firmly define pre-requisites for upper-level courses and the corresponding minimum required grades in these pre-requisites. The course content of the courses, especially discipline specific courses, should be clearly spelled out in the mutually agreed syllabi.

4. Coordinators/advisors: Appoint enthusiastic and open-minded people for these positions. Train them to become knowledgeable. Try to provide incentives for longevity. Finding the right people for these positions are most essential for the success of the program.

5. Orientation for new students: Develop an orientation program tailored specifically for the students of this program. Bring university experts on board for help. This is one of the most demanding activities that requires continuous update as new situations arise.

6. Other important items: Ensure timely issuance of visas, registration for courses, resolution of bursar requirements. Set up the rules for scholarships, if available.

\section{Conclusions}

ITU and SIUE signed a dual-diploma agreement in 2007, and successfully implemented the program for almost a decade. Over the years, SIUE was repeatedly praised by three different groups of ITU administrators for the quality of education it offered to the dualdiploma students, the dedication of its administrators to the success of the program, and its outstanding educational facilities. However, ITU terminated the program unilaterally in 2016 citing two reasons: 
1. The ranking of SIUE's industrial engineering program in the USA.

2. Negative feedback from the students regarding their educational experience at SIUE.

In this paper, we demonstrate that the reasons cited by ITU are not plausible. Based on our observations, we offer a plausible reason for the action of ITU; the motive of the ITU administrators to provide financial incentives to the newly-hired faculty members at ITU.

When the program ends, SIUE will not only lose substantial income, but also a large international group who has been contributing to the campus multi-cultural and intellectual capacities. Additionally, SIUE's Engineering School's graduation statistics will be negatively impacted, since almost all the students in this program graduated in four years.

The founding vice-rector of ITU expressed his feelings about the termination of the program in the following statement: "I am deeply sorry that the new administration of my university destroyed this successful program using unfounded excuses."

\section{REFERENCES:}

[1] Karacal, S. C., H. Sevim, 2011 "International Cooperation in an Industrial Engineering Dual-diploma Program," Proceedings of American Society of Engineering Education Conference (ASEE), Vancouver, Canada, June 26-29.

\section{Appendix}

Survey given to alumni in 2018. Student survey is very similar with minor edits on some questions.

1. The education I received at SIUE prepared me well for my professional life and/or graduate studies.

Strongly Disagree Disagree Agree Strongly Agree

Any comments:

2. The education I received at ITU prepared me well for my professional life and/or graduate studies.

Strongly Disagree Disagree Agree Strongly Agree

Any comments:

2-1) The guidance I received from the program coordinator at SIUE was: 
Unsatisfactory Satisfactory Good Very Good Excellent

Any comments:

2-2) The guidance I received from the program coordinator at ITU was:

Unsatisfactory Satisfactory Good Very Good Excellent

Any comments:

3-1) The professors at SIUE were knowledgeable in their field.

Strongly Disagree Disagree Agree Strongly Agree

Any comments:

3-2) The professors at ITU were knowledgeable in their field.

Strongly Disagree Disagree Agree Strongly Agree

Any comments:

4-1) The professors at SIUE were approachable and showed interest in me.

Strongly Disagree Disagree Agree Strongly Agree

Any comments:

4-2) The professors at ITU were approachable and showed interest in me.

Strongly Disagree Disagree Agree Strongly Agree

Any comments:

5-1) Overall, the education I received at SIUE was:

Unsatisfactory Satisfactory Good Very Good Excellent

Any comments:

5-2) Overall, the education I received at ITU was:

Unsatisfactory Satisfactory Good Very Good Excellent

Any comments:

6) Have you ever been surveyed by ITU administrators regarding your educational experience in the dual diploma program?

7) If the program were to continue, would you recommend it to a friend or relative?

8) In your opinion, what might be the reason(s) ITU administration terminated this program?

9) Please tell us your current occupation?

10) Any additional comments or suggestions you might make? 